\title{
16 COMPUTERISED ASSESSMENT OF ALCOHOL USE AND READINESS TO CHANGE IN SPANISH-SPEAKING EMERGENCY DEPARTMENT PATIENTS
}

doi:10.1136/injuryprev-2012-040590o.16

S Lotfipour, V Cisneros, W Hoonpongsimanont, S Roumani, B Chakravarthy, C Anderson. University of California, Irvine School of Medicine, USA

Background The rapid growth of the Latino population in the US requires increased attention for prevention, screening, and treatment for alcohol-related problems. We offer English and Spanishspeaking emergency department (ED) patients a computerised alcohol screening and brief intervention (CASI) programme. CASI utilises the Alcohol Disorders Identification Test (AUDIT) for screening, compares daily and weekly drinking to National Institute on Alcohol Abuse and Alcoholism (NIAAA) thresholds for safe drinking and provides a brief intervention as necessary.

Objectives To assess drinking patterns of Spanish-speaking patients using a bilingual CASI tablet.

Methods This retrospective study was conducted in a tertiary university hospital ED between 2006 and 2010. Data from 1816 Spanish-speaking ED patients was analysed using descriptive statistics, the $\chi^{2}$ test for independence, and the Kruskal-Wallis rank sum test for comparisons using quantitative variables.

Results Overall, $15 \%$ of Spanish-speaking patients were at-risk drinkers, and $5 \%$ had an AUDIT score consistent with alcohol dependency $(\geq 20)$. A higher percentage of Spanish-speaking males than females were at-risk drinkers or dependent. Spanish speaking males exhibited higher frequency of drinking days per week and higher number of drinks per day compared to females. Non-drinking behaviour increased in older patients and at-risk drinkers decreased. Males and females were ready to change their behaviour after intervention, $61 \%$ and $67 \%$ respectively.

Significance CASI found significant at-risk and dependent drinking behaviour in Spanish-speaking ED patients. The majority of patients were ready to change their drinking behaviour. More alcohol screening and brief intervention should be tested and become readily accessible for Spanish-speaking patients. 